\title{
ADA activity in the follicular fluid of infertile women with diminished ovarian reserve can act as a predictor of ovarian reserve
}

\author{
Gülşah İlhan $^{1 *}$, Besim H. Bacanakgil ${ }^{1}$, Ayşe Köse², Ayben Atıcı', \\ Şener Yalçınkaya ${ }^{1}$, Mevlüde Ayyıldız ${ }^{3}$
}

\begin{abstract}
${ }^{1}$ In Vitro Fertilization and Reproductive Endocrinology, Obstetrics and Gynecology, ${ }^{2}$ In Vitro Fertilization and Reproductive Endocrinology, Clinical Embryology, ${ }^{3}$ Clinical Biochemistry, Istanbul Research and Education Hospital, Health Sciences University, Istanbul, Turkey
\end{abstract}

Received: 13 December 2020

Accepted: 13 January 2021

\author{
*Correspondence: \\ Dr. Gülşah İlhan, \\ E-mail: gulsah.keskin.84@hotmail.com
}

Copyright: ( $)$ the author(s), publisher and licensee Medip Academy. This is an open-access article distributed under the terms of the Creative Commons Attribution Non-Commercial License, which permits unrestricted non-commercial use, distribution, and reproduction in any medium, provided the original work is properly cited.

\begin{abstract}
Background: Adenosine deaminase (ADA) catalyses the deamination of adenosine to inosine. In the human reproductive tract, the importance of enzymes that affect metabolism of adenosine, particularly ADA, has been emphasized. It is aimed to evaluate the plasma and follicular fluid (FF) activities of total ADA (ADAT) in infertile women and to determine its relation with ovarian reserve markers and in vitro fertilization (IVF) outcomes.

Methods: Plasma and FF activities of ADAT were measured in 106 infertile women. Its relation with ovarian reserve markers and IVF outcomes were determined.

Results: There was a significant difference in the ADAT activities between plasma and FF of infertile women $(\mathrm{p}<0.01)$. The activity of plasma ADAT was higher than FF ADAT in infertile women $(\mathrm{p}<0.01)$. The activity of FF ADAT in DOR group was higher than that of the others $(\mathrm{p}<0.01)$. In DOR group; the activity of FF ADAT activity had a negative correlation with BMI and a positive correlation with FSH and no relation with IVF outcomes.

Conclusions: Increased ADAT activity can lead to reduced adenosine levels, which might be resulted in disturbed fertility process. The activity of FF ADAT activity might be important for fertility work-up. Further studies are needed.
\end{abstract}

Keywords: ADA, Diminished ovarian reserve, Follicular fluid, Infertility

\section{INTRODUCTION}

Adenosine deaminase (ADA) is an enzyme and has a role in the deamination of $2^{\prime}$ deoxyadenosine and adenosine to $2^{\prime}$ deoxyinosine and inosine. ${ }^{1}$ There are three molecular forms, including ADA1, ADA1+cp and ADA2. The enzyme is distributed in all human cells including lymphocytes and monocytes and monocyte-macrophage system is the major source. ${ }^{2,3}$ Beside immune system development, ADA acts an important role in differentiation, proliferation, maturation and function of lymphocytes. Aditionally, it is essential for the maturation of blood monocytes to macrophages. Elevated serum enzyme activities have been reported with diseases those related to malignancies and immune system. ${ }^{4-7}$
ADA activity changes in diseases characterized by the alteration of cell-mediated immunity. ${ }^{1,4-7}$ Accordingly, ADA might be a marker of cell-mediated immunity.

In the human reproductive tract, the function of the enzymes that affect adenosine metabolism, especially ADA, have been investigated. The activity of ADA was evaluated in the male reproductive system. They signified that inhibition of ADA activity increases adenosine levels and it resulted an improvement of sperm fertilization. ${ }^{8,9}$ In addition, it is suggested that ADA receptors might have a role in capacitation and acrosome reaction. ${ }^{10}$ Due to the significance of ADA in the male reproductive system, it seemed logical that alteration in ADA activity to be associated with male infertility. ${ }^{11}$ For the female 
reproductive system, that women with elevated ADA activity have the highest risk for recurrent spontaneous abortion. ${ }^{12,13}$ It is also revealed that ADA activity shows fluctuations in the normal menstrual physiology. ${ }^{14}$ In addition, ADA activity was investigated during pregnancy. ${ }^{15-17}$ To the best of our knowledge, ADA activity has not yet been systematically addressed in the female infertility.

Oocyte capability to support embryonic development is recovered in the ovarian follicle. During follicular evaluation, the follicle has an antrum filled with a fluid called follicular fluid (FF) from the tertiary stage. FF is a key element influences mainly oocyte growth, maturation and nutrition. This fluid is a source of noninvasive biochemical markers, is easily available. Since FF constitutes a vital microenvironment for the development of oocytes, it seems logical to assume that some biochemical characteristics of FF surrounding the oocyte may imply ovarian reserve and may play a critical role in oocyte quality, fertilization potential, embryo development, and pregnancy rate. ${ }^{18-22}$ Accordingly, we assessed whether FF activity of ADAT is different between infertile women with different infertility etiologies.

So, we sought to investigate the activity of ADAT in the plasma and FF, and to analyze the relation with ovarian reserve and clinical parameters linked to IVF outcomes of women undergoing IVF/ICSI.

\section{METHODS}

This study was a retrospective cohort study. The data of all individuals, who underwent their IVF/ICSI at IVF Unit of Istanbul Research and Education Hospital from May $1^{\text {st }} 2019$ to July $31^{\text {st }} 2019$ were retrospectively reviewed. The study was approved by the ethics committee of the hospital. Patient characteristics and cycle parameters were collected from hospital database. Only one IVF cycle of each patient was evaluated within the study time frame.

\section{Inclusion criteria}

The women were between 23-45 years old, unable to conceive naturally for at least 1 year, had an infertility etiology of diminished ovarian reserve (DOR), tubal factor (TF), male factor (MF) or unexplained infertility. They had no infectious disease or inflammation. Individuals who met the inclusion criteria were included.

\section{Exclusion criteria}

Patients were excluded if they had two or more type of infertility etiologies, diseases of the immune system, hematologic malignancies, ovarian tumors, endocrine disorders (hyperprolactinemia, diabetes mellitus, thyroid dysfunction, Cushing syndrome, and congenital adrenal hyperplasia), uterine abnormality or smoking. Patients with chronic use of any medication were also excluded.

A total of 106 women were eligible and enrolled in this study. Blood specimens were drawn before oocyte retrieval. FF samples from the first aspirated follicle was used for ADAT measurement from infertile women who underwent oocyte retrieval for IVF-ICSI. Venous blood samples were collected in the presence of EDTA, and plasma was stored at $-20^{\circ} \mathrm{C}$. ADAT activity was evaluated according to the method of Giusti and Galanti. $^{23}$

Complete blood counts, day 3 follicle-stimulating hormone $(\mathrm{FSH})$, anti-Müllerian hormone $(\mathrm{AMH})$ were evaluated in all subjects. Age, body mass index (BMI), infertility etiology, duration of infertility, treatment protocol, cycle parameters including estradiol (E2) and progesterone ( $\mathrm{P} 4)$ on $\mathrm{hCG}$ day, number of oocyte retrieved, MII oocyte, 2PN (pronucleus), and embryos transferred and pregnancy rate were assessed. For controlled ovarian stimulation, we used GnRH-antagonist protocol. The GnRH-antagonist protocol was started on day 3 of the menstrual cycle with either hMG or rFSH (Menogon, Ferring, Istanbul, Turkey or GonalF 75IU ampules; Serono, Istanbul, Turkey). Cetrotide GnRHantagonist (Cetrorelix acetate, Merck Serono, Istanbul, Turkey) was administered on stimulation day 6 . Transvaginal ultrasonography, together with measuring of blood estradiol (E2), were used to assess the ovarian response, and adjust the gonadotropin dose. When at least two follicle were $\geq 18 \mathrm{~mm}$, Ovitrelle 250 micrograms (choriogonadotropin-alfa, Merck Serono, Istanbul, Turkey) was ordered to trigger ovulation. Oocyte retrieval was done at hour 35-36 after hCG injection. An oocyte retrieval was performed using a 17-gauge needle under transvaginal ultrasound guidance. The oocytecorona complexes were removed, ICSI was done after two hours of incubation. Embryos were transferred on day 3 or day 5. A maximum of two embryos were transferred each time when the patient was older than 35 years old.

DOR is defined by the presence of two of the following three features: (1) maternal age $\geq 40$ years or any other risk factor for poor response, (2) previous poorly responsive cycles ( $\leq 3$ oocytes retrieved), (3) an abnormal ovarian reserve test $(\mathrm{AMH}<0.5-1.1 \mathrm{ng} / \mathrm{mL}$ or antral follicle count $<5-7$ follicles). ${ }^{24}$ Tubal factor infertiliy (TF) was defined as the blockage of tuba uterina bilaterally on hysterosalpingography that was confirmed by laparoscopy. Unexplained infertility was defined as the inability to concieve despite 1 year of unprotected intercourse that is not explained by anovulation, tubal pathology, impaired sperm quality, or any other etiology of infertility. Male factor (MF) infertility was defined as infertility caused primarily by male factors including abnormal semen parameters or function, endocrine, anatomical, genetic, immunological or functional 
abnormalities of the reproductive tract; chronic illness, and sexual dysfunctions.

\section{Statistical analysis}

IBM SPSS Statistics 22.0 program was used for statistical analysis. When evaluating the study data, the suitability of the parameters to normal distribution was evaluated by Kolmogorov-Smirnov test. Descriptive statistical methods (mean, standard deviation) were used to evaluate the study data. In the comparison of quantitative data; Oneway ANOVA test was used to compare the normal distribution parameters. Tukey HSD test was used to isolate statistically significance among the groups. Kruskal Wallis test was used for comparison of nonnormally distributed parameters. Mann Whitney U test was used to isolate statistically significance among the groups. In addition, Mann Whitney-U-test was used to compare the non-normal distribution parameters among the two groups. Chi-square test was used to compare qualitative data. Spearman's rho correlation analysis was used to investigate the relationships between the parameters. Significance was evaluated at $p<0.05$.

\section{RESULTS}

A total of 106 infertile women were enrolled in the study. Thirty-three of the women had diminished ovarian reserve, 22 had tubal factor, 21 had unexplained infertility and 30 had male factor infertility. Distribution of demographic features and cycle parameters were given in Table 1.

Table 1: Distribution of demographic features and cycle parameters.

\begin{tabular}{|c|c|c|c|c|c|}
\hline \multirow[b]{2}{*}{ Variables } & MF & DOR & TF & Unexplained & \multirow[b]{2}{*}{ P value } \\
\hline & $\begin{array}{l}\text { Mean } \pm \text { SD; } \\
\text { median }\end{array}$ & $\begin{array}{l}\text { Mean } \pm \text { SD; } \\
\text { median }\end{array}$ & $\begin{array}{l}\text { Mean } \pm \text { SD; } \\
\text { median }\end{array}$ & $\begin{array}{l}\text { Mean } \pm \text { SD; } \\
\text { median }\end{array}$ & \\
\hline Age (years) & $30.83 \pm 5.27$ & $33.67 \pm 4.85$ & $31.27 \pm 4.93$ & $31.48 \pm 4.57$ & $0.112^{1}$ \\
\hline BMI $\left(\mathrm{kg} / \mathrm{m}^{2}\right)$ & $22.40 \pm 2.19$ & $22.58 \pm 2.51$ & $22.41 \pm 2.36$ & $23.05 \pm 2.78$ & $0.794^{1}$ \\
\hline Duration of infertility (days) & $4.33 \pm 2.63 ; 4$ & $4.36 \pm 2.65 ; 4$ & $4.09 \pm 2.67 ; 3.5$ & $4.19 \pm 2.25 ; 4$ & $0.966^{2}$ \\
\hline Duration of COH (days) & $9.20 \pm 0.71 ; 9$ & $9.09 \pm 0.76 ; 9$ & $9.14 \pm 0.64 ; 9$ & $9.14 \pm 0.48 ; 9$ & $0.766^{2}$ \\
\hline AMH (ng/ml) & $4.07 \pm 2.29 ; 3.24$ & $0.82 \pm 0.71 ; 0.63$ & $4.38 \pm 3.78 ; 3.68$ & $6.21 \pm 5.34 ; 4.22$ & $0.001 * * 2$ \\
\hline FSH $(\mathrm{mIU} / \mathrm{ml})$ & $7.76 \pm 2.92 ; 8.08$ & $10.86 \pm 5.15 ; 9.96$ & $8.78 \pm 3.36 ; 7.98$ & $8.11 \pm 3.52 ; 7.54$ & $0.028 * 2$ \\
\hline $\begin{array}{l}\text { E2 levels on the day of hCG } \\
\text { (pg/ml) }\end{array}$ & $\begin{array}{l}1425.74 \pm 1121.71 \\
1019.28\end{array}$ & $\begin{array}{l}705.91 \pm 495.78 \\
545.49\end{array}$ & $\begin{array}{l}1638.01 \pm 1135.62 \\
1437.31\end{array}$ & $\begin{array}{l}1433.35 \pm 914.41 \\
1259.27\end{array}$ & $0.001 * * 2$ \\
\hline $\begin{array}{l}\text { P4 levels on the day of hCG } \\
\text { (ng/ml) }\end{array}$ & $1.77 \pm 1.18 ; 1.43$ & $1.41 \pm 0.56 ; 1.29$ & $2.10 \pm 1.47 ; 1.71$ & $1.62 \pm 1.03 ; 1.31$ & $0.451^{2}$ \\
\hline Oocytes retrieved (n) & $7.87 \pm 3.73 ; 7.5$ & $3.30 \pm 1.89 ; 3$ & $8.73 \pm 3.89 ; 8$ & $9.57 \pm 5.88 ; 8$ & $0.001 * * 2$ \\
\hline \multirow[t]{2}{*}{ MII oocyte (n) } & $6.53 \pm 3.34 ; 6$ & $2.76 \pm 1.66 ; 2$ & $7.18 \pm 3.62 ; 7$ & $7.43 \pm 4.13 ; 6$ & $0.001 * * 2$ \\
\hline & $\mathrm{n} ; \%$ & $\mathrm{n} ; \%$ & n; \% & $\mathrm{n} ; \%$ & \\
\hline \multirow{3}{*}{$\begin{array}{l}\text { Embryos transferred } \\
\text { (n) }\end{array}$} & $7 ; 23.3$ & $6 ; 18.2$ & $1 ; 4.5$ & $2 ; 9.5$ & \multirow{3}{*}{$0.309^{3}$} \\
\hline & $14 ; 46.7$ & $12 ; 36.4$ & $12 ; 54.5$ & $13 ; 61.9$ & \\
\hline & $9 ; 30$ & $15 ; 45.5$ & $9 ; 40.9$ & $6 ; 28.6$ & \\
\hline
\end{tabular}

${ }^{1}$ Oneway ANOVA test; ${ }^{2}$ Kruskall Wallis test; ${ }^{3} \mathrm{Ki}-$ Kare test; ${ }^{*} \mathrm{p}<0.05 ; * * \mathrm{p}<0.01$; AMH: Anti-mullerian Hormone; BMI: Body mass index; DOR: Diminished ovarian reserve; E2: Estradiol; FSH: Follicle-stimulating hormone; MF: Male factor; MII: Metaphase II; n: number; P4: Progesteron; TF: Tubal Factor

Table 2: Plasma and follicular fluid ADAT activities of infertile women according to infertility etiology and comparision of complete blood count parameters of the groups.

\begin{tabular}{|c|c|c|c|c|c|}
\hline \multirow{2}{*}{ Variables } & MF & DOR & TF & Unexplained & \multirow{2}{*}{ P value } \\
\hline & Mean \pm SD; median & Mean \pm SD; median & Mean \pm SD; median & Mean \pm SD; median & \\
\hline Lymphocyte $\left(10^{9} / 1\right)$ & $2.53 \pm 0.76$ & $2.38 \pm 0.65$ & $2.17 \pm 0.71$ & $2.44 \pm 0.49$ & ${ }^{1} 0.273$ \\
\hline Monocyte $\left(10^{9} / 1\right)$ & $0.57 \pm 0.19 ; 0.54$ & $0.51 \pm 0.16 ; 0.49$ & $0.48 \pm 0.13 ; 0.47$ & $0.53 \pm 0.14 ; 0.52$ & ${ }^{2} 0.428$ \\
\hline Eosinophil $\left(10^{9} / \mathrm{l}\right)$ & $0.15 \pm 0.11 ; 0.12$ & $0.15 \pm 0.11 ; 0.13$ & $0.16 \pm 0.13 ; 0.14$ & $0.19 \pm 0.21 ; 0.10$ & ${ }^{2} 0.973$ \\
\hline \multirow{2}{*}{ ADAT (U/L) } & MF & DOR & TF & Unexplained & \multirow{2}{*}{$P$ value } \\
\hline & Mean \pm SD; median & Mean \pm SD; median & Mean \pm SD; median & Mean $\pm S D ;$ median & \\
\hline Plasma & $7.93 \pm 1.65$ & $7.80 \pm 1.05$ & $7.18 \pm 1.93$ & $7.16 \pm 1.58$ & ${ }^{1} 0.163$ \\
\hline Follicular fluid & $4.58 \pm 0.85 ; 4.55$ & $6.68 \pm 1.14 ; 6.6$ & $4.23 \pm 1.07 ; 4.3$ & $4.45 \pm 1.03 ; 4.4$ & ${ }^{2} 0.001 * *$ \\
\hline
\end{tabular}

${ }^{1}$ Oneway ANOVA test; ${ }^{2}$ Kruskall Wallis test; ${ }^{* *} \mathrm{p}<0.01$; DOR: Diminished ovarian reserve; MF: Male factor; TF: Tubal Factor 
AMH level of DOR group was significantly lower than that of the other groups $(p<0.01)$. There was no statistically significant difference among the other groups $(\mathrm{p}>0.05)$.

FSH level of DOR group was significantly higher than that of the other groups $(\mathrm{p}<0.05)$. There was no statistically significant difference among the other groups $(\mathrm{p}>0.05)$.

Mean level of serum estradiol on the day of hCG administration $(\mathrm{p}<0.01)$, total number of oocytes retrieved $(\mathrm{p}<0.01)$ and MII oocyte count $(\mathrm{p}<0.01)$ of DOR group were significantly lower than that of the other groups. There was no statistically significant difference among the other groups $(\mathrm{p}>0.05)$.

The complete blood count of the infertility groups is given in Table 2. Plasma lymphocyte, monocyte and eosinophil counts were not statistically different between groups $(\mathrm{p}>0.05)$.

Plasma and FF ADAT activities of infertile women according to infertility etiology are shown in Table 2. Activity of plasma ADAT was significantly higher than activity of FF ADAT in all of the infertile groups $(\mathrm{p}<0.01)$. Activity of FF ADAT was higher in DOR group than the others $(\mathrm{p}<0.01)$. There was no statistically significant difference among the other groups $(\mathrm{p}>0.05)$.

Tablo 3. Relation of ADAT activity with ovarian reserve markers and cycle parameters in DOR group.

\begin{tabular}{|c|c|}
\hline \multirow{2}{*}{ DOR group } & \multirow{2}{*}{$\begin{array}{l}\text { FF ADAT(U/I) } \\
\text { R }\end{array}$} \\
\hline & \\
\hline Age (years) & -0.001 \\
\hline BMI $\left(\mathrm{kg} / \mathrm{m}^{2}\right)$ & $-0.507 * *$ \\
\hline Day 3 FSH (mIU/ml) & $0.352 *$ \\
\hline AMH (ng/mL) & 0.081 \\
\hline Monocyte count $\left(10^{9} / 1\right)$ & 0.147 \\
\hline $\begin{array}{l}\text { E levels on the day of hCG } \\
(\mathrm{pg} / \mathrm{ml})\end{array}$ & 0.007 \\
\hline $\begin{array}{l}\text { P4 levels on the day of hCG } \\
(\mathrm{ng} / \mathrm{ml})\end{array}$ & 0.156 \\
\hline Duration of COH (days) & -0.143 \\
\hline Oocytes retrieved (n) & 0.057 \\
\hline MII Oocyte (n) & -0.020 \\
\hline Embryos transferred (n) & 0.318 \\
\hline 2PN (n) & 0.318 \\
\hline${ }^{4}$ Pregnancy & Mean \pm SD \\
\hline Negative & $6.79 \pm 1.15$ \\
\hline Positive & $6.53 \pm 1.14$ \\
\hline \multicolumn{2}{|c|}{$\begin{array}{l}\text { r: Spearman's rho correlation cofficient }{ }^{4} \text { Mann-Whitney U } \\
\text { test; }{ }^{*} \text { p }<0.05 \text {; } * * \text { p }<0.01 \text {; AMH: Anti-mullerian Hormone; } \\
\text { BMI: Body mass index; DOR: Diminished ovarian } \\
\text { reserve; E2: Estradiol; FF: Follicular fluid; FSH: Follicle- } \\
\text { stimulating hormone; MF: Male factor; MII: Metaphase II; } \\
\text { n: number; P4: Progesteron; TF: Tubal Factor; 2PN: } \\
\text { pronucleus. }\end{array}$} \\
\hline
\end{tabular}

The relation of ADAT activity with BMI showed a negative correlation in DOR group ( $\mathrm{r}=-0.507)$. Additionally, ADAT activity of DOR group and FSH levels, showed a positive correlation $(\mathrm{r}=0.352)$ (Table 3$)$.

\section{DISCUSSION}

In the present study; a significant difference in the ADAT activities between plasma and FF of infertile women was found. The activity of plasma ADAT was higher than FF in infertile individuals. Aditionally, the activity of FF ADAT in DOR group was higher than that of the others. FF enzyme activity of DOR group had a correlation with one of ovarian reserve markers (FSH). However, any relationship did not observed with IVF outcomes. According to our results, it can be concluded that the ADAT activity in the FF of infertile women with DOR may act as a predictor of ovarian reserve.

Infertility is defined as the inability to concieve within 12 months of unprotected sexual intercourse. ${ }^{25}$ Though, IVF is a good treatment option for infertility has become widely accepted, DOR is one of the most bothersome causes of the failure of IVF attempts. ${ }^{25}$ DOR is demonstrated by markers such as the decrease in the antral follicle count, the increase in the Day3 FSH, and the decrease in the AMH. ${ }^{26,27}$ In our study; activity of FF ADAT was higher in DOR group than the others $(\mathrm{p}<0.01)$ and it is showed that ADAT activity in FF of DOR group has a positive correlation with FSH and a negative correlation with BMI. There was a statistically significant correlation between follicle ADAT level and FSH level at $35.2 \% \quad(\mathrm{p}<0.05)$. Follicle ADAT levels increased by 0.352 units while FSH increased. There was a statistically significant correlation between follicle ADAT level and BMI at $50.7 \%(\mathrm{p}<0.01)$. Follicle ADAT level decreases by 0.507 units while BMI increases.

The activity of ADA shows changes in diseases characterized by the alteration of cell-mediated immunity. ${ }^{4-7}$ However, the etiology of elevated ADAT activity in infertile women with DOR are not clear. Increased ADAT activity in infertile women with DOR can result in reduction of adenosine availability. Since our findings suggest that ADAT activity in FF can indicate diminished ovarian reserve, increased enzymatic activity and decreased adenosine level might have a role in ovarian reserve in infertile women. Although granulosa-luteal cells predominate in FF, it was found that monocytes-macrophages comprise $5-15 \%$ of human follicular tissue cells. ${ }^{28}$ As the main source of ADA in plasma is the monocyte-macrophage system, it is rational that higher numbers of plasma monocytes might be a reason for increased intrafollicular ADA activity in infertile individuals with DOR. Nevertheless, there were no significant differences in the number of lymphocytes, monocytes and eosinophils between different infertility etiologies. Moreover, any significant correlation was not found between ADAT activity and serum monocyte count in infertile women with DOR in our study 
( $p>0.05)$. Increased intrafollicular monocyte-macrophage content in infertile women with DOR might be speculated as a cause of increased intrafollicular enzymatic activity but further studies are needed.

In the literature there are few studies evaluating intrafollicular ADAT activity. A study of Celik et al concluded that the mean follicular ADA was higher in $\mathrm{GnRH}$-antagonist group than GnRH-agonist group. In our study; GnRhH-antagonist protocol was applied to all infertile patients. ${ }^{29}$ Most of the ADA studies about infertility assess enzymatic activity of serum ADA. In the literature; increased levels of ADA was found to be responsible in abortions via decreasing adenosine levels. Adenosine is an important local hormone regulating blood flow, platelet aggregation, smooth muscle physiology and neurotransmission. ${ }^{12}$ Decreased ADA stated to have a role in sustaining normal pregnancy via increasing adenosine level. An increase in serum ADAT, and ADA2 activities in women with recurrent spontan abortion was demonstrated. ${ }^{12}$ In one another study; it was stated that infertile women who get pregnant after IVFET had significantly lower serum concentrations of ADA1, significantly increased levels of serum ADA, monocyte and lymphocyte counts as indicators of activated cellular immunity. ${ }^{30}$

Our study has some limitations. Study population was small and ADA enzyme activity could be calculated as ADA1 and ADA2 rather than ADAT. Unfortunately, this is a result of our laboratory conditions.

\section{CONCLUSION}

Given the results, ADAT activity in FF of DOR group on the day of oocyte retrieval has a positive relation with ovarian reserve marker (FSH). To further evaluate the function of ADAT in the FF on the day of oocyte retrieval in predicting IVF outcomes, the correlation of the ADAT levels in FF and IVF outcomes were identified. We demonstrated that ADAT activity in FF on the day of oocyte retrieval could not predict IVF outcomes. Best of our knowledge, this is the first study assessing intrafollicular ADA activity and the relation with ovarian reserve markers and IVF outcomes. Further researches are needed to clarify the mechanisms by which the activity of ADAT may affect and regulate the fertility and the reproductive process of humans.

Funding: No funding sources

Conflict of interest: None declared

Ethical approval: The study was approved by the Institutional Ethics Committee

\section{REFERENCES}

1. Muraoka T, Katsuramaki T, Shiraishi H, Yokoyama M. Automated enzymatic measurement of adenosine deaminase isoenzyme activities in serum. Anal Biochem. 1990;187:268-72.
2. Gakis C. Adenosine deaminase (ADA) isoenzymes ADA1 and ADA2: diagnostic and biological role. Eur Respir J. 1996;9:632-3.

3. Skarar DN, Hossain I, Shoab AKM, Amin R. Adenosine Deaminase (ADA) in Tuberculous Meningitis. Bangladesh J Med. 2014;25:61-71.

4. Mishra SK, Sah JP, Awasthi G, Sharma R. Adenosine deaminase activity in plasma of children with acute lymphoblastic leukemia. J Nepal Health Res Counc. 2009;7:93-7.

5. Adams A, Harkness RA. Adenosine deaminase activity in thymus and other human tissues. Clin Exp Immunol. 1976;26:647-9.

6. Kobayashi F, Ikeda T, Marumo F, Sato C. Adenosine deaminase isoenzymes in liver disease. Am J Gastroenterol. 1993;88:266-71.

7. Gakis C, Calia G, Naitana A, Pirino D, Serru G. Serum adenosine deaminase activity in HIV positive subjects: a hypothesis on the significance of ADA2. Panminerva Med. 1989;31:107-13.

8. Monks N, Fraser L. Inhibition of adenosinemetabolizing enzymes modulates mouse sperm fertilizing ability: a changing role for endogenously generated adenosine during capacitation. Gamete Res 1988;21:267-76.

9. Crabbe M. The development of a qualitative assay for male infertility from a study of enzymes in human semen. J Reprod Fertil. 1977;51:73-6.

10. Minelli A, Allegrucci C, Piomboni P, Mannucci R, Lluis C, Franco R. Immunolocalization of A1 adenosine receptors in mammalian spermatozoa. $\mathrm{J}$ Histochem Cytochem. 2000;48:1163-71.

11. Rostampour F, Biglari M, Vaisi-Raygani A, Salimi $\mathrm{S}$, Tavilani $\mathrm{H}$. Adenosine deaminase activity in fertile and infertile men. Andrologia. 2012;44(1):586-9.

12. Hitoglou S, Zournatzi V, Gougoustamou D, Hatzistilianou M, Tzafettas J. Adenosine deaminase activity and its isoenzyme pattern in women with recurrent spontaneous abortions. Gynecol Obstet Invest. 2004;58:126-9.

13. Nicotra M, Bottini N, La Torre M, Amante A, Bottini E, Gloria-Bottini F. Repeated spontaneous abortion. Cooperative effects of ADA and ACP1 genetic polymorphisms. Am J Reprod Immunol. 2007;58(1):1-10.

14. Setarehbadi R, Hosseinipanah SM, Vatannejad A, Karimi M, Vaisi-Raygani A, Tavilani H. Adenosine deaminase activity during menses, follicular and luteal phases of the menstrual cycle. Eur J Obstet Gynecol Reprod Biol. 2011;155:233-4.

15. Yoneyama Y, Suzuki S, Sawa R, Otsubo Y, Miura A, Kuwabara Y, et al. Serum adenosine deaminase activity and its isoenzyme pattern in women with normal pregnancies. Arch Gynecol Obstet. 2003;267:205-7.

16. Mokhtari M, Hashemi M, Yaghmaei M, Molashahi F, Shikhzadeh A, Niazi A, et al. Serum adenosine deaminase activity in gestational diabetes mellitus 
and normal pregnancy. Arch Gynecol Obstet. 2010;281:623-6.

17. Lee S, Hwang H, Kim B, Kim M, Lee J, Park Y, et al. Changes in serum adenosine deaminase activity during normal pregnancy. $\mathrm{J}$ Korean Med Sci. 2007;22:718-21.

18. Tong J, Sheng S, Sun Y, Li H, Li WP, Zhang C, et al. Melatonin levels in follicular fluid as markers for IVF outcomes and predicting ovarian reserve. Reproduction. 2017;153(4):443-51.

19. Rao M, Zhou F, Tang L, Zeng Z, Hu S, Wang Y, et al. Follicular fluid humanin concentration is related to ovarian reserve markers and clinical pregnancy after IVF-ICSI: a pilot study. Reprod Biomed Online. 2019;38(1):108-17.

20. de la Barca JMC, Boueilh T, Simard G, Boucret L, Ferré-L'Hotellier V, Tessier L, et al. Targeted metabolomics reveals reduced levels of polyunsaturated choline plasmalogens and a smaller dimethylarginine/arginine ratio in the follicular fluid of patients with a diminished ovarian reserve. Hum Reprod. 2017;32(11):2269-78.

21. Cavallo IK, Dela Cruz C, Oliveira ML, Del Puerto HL, Dias JA, Lobach VN, et al. Angiotensin-(1-7) in human follicular fluid correlates with oocyte maturation. Hum Reprod. 2017;32:1318-24.

22. Buyuk E, Asemota OA, Merhi Z, Charron MJ, Berger DS, Zapantis A, et al. Serum and follicular fluid monocyte chemotactic protein-1 levels are elevated in obese women and are associated with poorer clinical pregnancy rate after in vitro fertilization: a pilot study. Fertil Steril. 2017;107:632-40.

23. Giusti G, Galanti B. Colorimetric method. In: Methods of Enzymatic Analysis, 3rd edn. Germany Verlag Chemie, Weinheim: Berlin; 1984:315-323.

24. Ferraretti A, La Marca A, Fauser BC, Tarlatzis B, Nargund G, Gianaroli L, ESHRE working group on
Poor Ovarian Response Definition. ESHRE consensus on the definition of 'poor response'to ovarian stimulation for in vitro fertilization: the Bologna criteria. Hum Reprod. 2011;26(7):1616-24.

25. Rad SS, Abbasalizadeh S, Haghjo AG, Sadagheyani M, Montaseri A, Rad JS. Evaluation of the melatonin and oxidative stress markers level in serum of fertile and infertile women. Int $\mathrm{J}$ Reprod Biol Med. 2015;13:439-44.

26. Aydın GA, Yavuz A, Terzi H, Kutlu T. Assessment of the relationship of basal serum anti-Mullerian hormone levels with oocyte quality and pregnancy outcomes in patients undergoing ICSI. Int J Reprod Biol Med. 2015;13:231-6.

27. Tal R, Seifer DB. Ovarian reserve testing: a user's guide. Am J Obstet Gynecol. 2017;217(2):129-40.

28. Loukides JA, Loy AR, Edwards R, Honig J, Visintin I, Polan ML. Human follicular fluids contain tissue macrophages. J Clin Endocrinol Metab. 1990;71(5):1363-7.

29. Celik E, Celik O, Kumbak B, Yilmaz E, Turkcuoglu I, Simsek Y, et al. Comparative study on oxidative and antioxidative markers of serum and follicular fluid in GnRH agonist and antagonist cycles. J Assist Reprod Genet. 2012;29(11):1175-83.

30. Hatzistilianou M, Antoniades D, Zournatzi V, Pappa $\mathrm{S}$, Antoniades M, Koiou K, et al. Isoenzymes of adenosine deaminase and metalloproteinases as biomarkers in in vitro fertilization and embryo transfer. Int J Immunopathol Pharmacol. $2011 ; 24(1): 25-31$.

Cite this article as: İlhan G, Bacanakgil BH, Köse A, Atıcı A, Yalçınkaya Ş, Ayyıldız M. ADA activity in the follicular fluid of infertile women with diminished ovarian reserve can act as a predictor of ovarian reserve. Int J Reprod Contracept Obstet Gynecol 2021;10:452-7. 